Volume 8

Issue 2 July

Article 8

July 1981

\title{
Women and Chronic Renal Failure: Some Neglected Issues
}

Nancy G. Kutner

Emory University

Heather L. Gray

Emory University

Follow this and additional works at: https://scholarworks.wmich.edu/jssw

Part of the Clinical and Medical Social Work Commons, Social Work Commons, and the Urology Commons

\section{Recommended Citation}

Kutner, Nancy G. and Gray, Heather L. (1981) "Women and Chronic Renal Failure: Some Neglected Issues," The Journal of Sociology \& Social Welfare: Vol. 8 : Iss. 2 , Article 8.

Available at: https://scholarworks.wmich.edu/jssw/vol8/iss2/8 
WOMEN AND CHRONIC RENAL FAILURE: SOME NEGLECTED ISSUES

Nancy G. Kutner

Emory University
Heather L. Gray

Emory University

\begin{abstract}
It has been assumed until recently that chronic renal failure is more prevalent among men than among women, but data now indicate that at least half of all renal patients are women. The literature continues to focus on adjustment problems of male patients, espectally sexual adjustment and job-loss problems, and to assume that women can adjust more easily because of their ability to maintain the homemaker role. However, women patients whose work status is that of homemaker are found to have the highest depression scores, and job loss results in low satisfaction for those who have held meaningful outside jobs. Women patients are not necessarily more satisfied with their sexual life than are men patients. Questions can also be raised about women patients' access to treatment alternatives associated with optimal patient outcomes.
\end{abstract}

Approximately 55,000 persons in the United States have experienced chronic renal failure (also known as end-stage renal disease or "ESRD") and are receiving some form of dialysis therapy (Gutman et a1., 1981). Without maintenance dialysis or a successful kidney transplant, patients whose kidneys have failed would die.

Adjustment to renal failure and to dialysis therapy is inherently stressful for patients; frequently noted reactions include anxiety, depression, and loss of self-esteem (Reichsman and Levy, 1972; Abram, 1974; Anger, 1975). Although the dialysis process restores a more normal fluid and electrolyte balance and raises patients' hematocrit, many dialysis patients continue to complain of fatigue. Fatigue, dialysis treatment schedules, and employers' reluctance to hire renal patients contribute to a lowered employment rate among patients who have gone on dialysis (Kutner et al., 1980). Marked reduction in interest in sex and ability to perform sexually are common among dialysis patients (Levy, 1978a).

Although recent data indicate that half of the persons in the U.S. who have experienced renal failure are women, existing literature on kidney patients tends to focus on adjustment problems of male patients 
and to assume that women adjust better or more easily than men (Czaczkes and De-Nour, 1978:149). Moreover, there is little recognition of structural arrangements in the provision of dialysis therapy which tend to benefit men more than women.

\section{LITERATURE REVIEW}

Financial coverage of dialysis treatments was assumed by Medicare In September, 1972.1 Before 1972, when there were few dialysis machines available and the cost of treatment was almost $\$ 40,000 /$ year per patient, there was a careful selection of ESRD patients who were to receive dia1ysis through an artificial kidney machine. These patients were typically young and had few medical complications in addition to their kidney failure.

It appears that dialysis patients prior to 1972 were also typically male. Evans et al. (1981) report that in 1967 male patients on hemodialysis (the dominant type of dialysis therapy) outnumbered female patients three to one. Data collected in 1978 in a national sample survey, however, indicated that the dialysis patient population was divided almost equally between males $(49.2 \%)$ and females $(50.8 \%)$. Similarly, our own survey in January, 1980, of the nine centers in the Atlanta SMSA which provide maintenance dialysis therapy to chronic renal failure patients indicated that 500 patients were being treated; 245 of these patients were male and 255 patients were female. ${ }^{2}$ It seems reasonable to conclude with Evans et a1. (1981:489) that since the passage of the Medicare legislation, women have had greater access to dialysis.

In the few studies which have focused on women as well as men renal patients, there is the suggestion that women are less likely than men to experience a significant change in social role as a consequence of renal failure. It is assumed that women's "typical" social role is that of homemaker and that women can more easily continue to fill this role de-

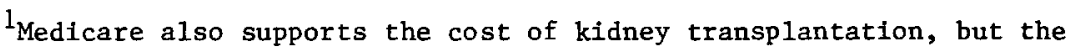
number of patients who receive transplants is quite small in comparison to the number who are on maintenance dialysis therapy.

2 These nine facilities treat relatively stable, chronic patients. Dialysis units whithin two hospitals in the metropolitan area also provide treatment to acutely ill patients; these patients are transferred to another facility when they are stabilized. 
spite their chronic illness than men can continue to fill their stereotypical role, i.e. paid employment outside the home.

of 25 patients studied by Goldberg et al. (1972) following initiation of dialysis therapy, only seven were classified as "productive" (i.e. working), and six of these seven patients were women. While only one of the ten male patients (10\%) remained gainfully employed, six of the fifteen women patients (40\%) remained active as homemakers. (However, none of the women were employed outside the home.) Similarly, Reichsman and Levy (1972), who studied 25 patients dialyzing between 1964-1968, found that ten of the eighteen men (56\%) were active 0-25\% of their "available time," while six of the seven women (86\%) were active $75-100 \%$ of their "available time." Activity in the latter study included paid employment, housework, or school enrollment, and "available time" was defined as time which could be used for these pursuits, excluding time spent dialyzing or being hospitalized.

A more recent study (Burns and Johnson, 1976) of 102 renal patients reported a decline in employment among men patients from $70 \%$ to $13 \%$ and a decline in employment among women patients from $38 \%$ to $0 \%$. The researchers indicated that women patients in the latter category then tended to become homemakers.

It may be an oversimplification to assume that women have fewer problems than do men in adjusting to renal disease because women can continue to be homemakers or can more easily shift from outside employment to homemaking activities. Many homemaking chores are more physically demanding than an outside job, and energy level tends to be significantly lowered for renal patients. Homemaking chores may offer less sense of accomplishment to a woman than holding an outside job, if only because of the financial reward which accompanies the latter. Rosenfield (1980:37), comparing depression scores for non-disabled men and women, reports that "when the wife is not working--when the division of labor is traditional--women have much higher levels of depressive symptoms than men."

Male patients may experience lowered self-esteem when kidney disease interferes with the patient's fulfilling the status of main income-earner for the family or contributes to sexual impotence. Levy (1978:330) points out that these two outcomes may frequently be related for men, increasing the probability of sexual dysfunction over and above that which can be expected from the physical and endocrinologic changes associated with renal disease: 
In a household in which the male is unable to work and therefore home most of the day, with the woman of the house of ten assuming some financial responsibility by working, the male patient of ten participates more in household activity. Among men whose masculine identity is tenuous, such role reversal may produce sexual dysfunction.

Although Levy (1973) found in a survey that women dialysis patients had become less interested in sexual relations and were less likely to experience orgasm, he did not posit a concomitant decreased sense of femininity among women. It appears that the issue of sexual dysfunction among women renal patients is generally assigned less importance than is the issue of sexual dysfunction among male patients.

Although they suggested that women can adjust more easily than men to life on dialysis, Relchsman and Levy (1972:861) reported that women patients were more likely than men to express feelings of anxiety about who would care for their children if they should die. This is the only reference we have found in the literature to a source of emotional distress which is more problematic for women than for men who have endstage renal disease. As we have noted, decline in employment and decreased sexual response are reported as characteristic of women patients who are on dialysis, but these are not viewed as problems for women, while they are viewed as problems for men.

\section{METHOD}

\section{Source of Data}

Research on the interrelation of medical, psychosocial, and vocational characteristics of chronic renal failure patients was initiated at Emory University's Center for Rehabilitation Medicine in 1978. Between January, 1978, and June, 1980, 150 patients were evaluated by means of written psychological tests and a semi-structured interview as we11 as assessment of physical strength and cognitive-motor skills. The large majority $(91 \%)$ of these patients were undergoing maintenance dialysis therapy (primarily hemodialysis) at the time of their evaluation; the remainder had received a transplant.

Patients were 1dentified through their use of nine dialysis facilities in the Atlanta metropolitan area and through their affiliation with a local chapter of an organization for kidney patients. ${ }^{3}$ The re-

3 This organization is the National Association of Patients on Hemodialysis and Transplantation, or "NAPHT." 
sulting study population closely approximates the existing race and sex composition of the Atlanta in-center dialysis population as well as the percentage of patients dialyzing at each facility.

\section{Nature of Sample}

This paper focuses primarily on data obtained from 23 white women and 27 black women who were on maintenance dialysis therapy due to chronic renal failure. Median age of the white women was 34 , with a range of 18 to 67; they had been on dialysis for an average of 27.4 months. Median age of the black women was 47, with a range of 26 to 70; these women had been dialyzing for an average of 24.3 months. This age difference stems from a difference in etiology of renal disease for the two races. The most frequently recorded diagnosis for black patients was hypertension. Because white patients were more likely to have developed renal disease due to congenital abnormalities or chlldhood infections, their renal failure tended to occur earlier in life.

Only six black women in our sample (22\%) were currently married; fourteen of the white women $(61 \%)$ were currently married. The average years of schooling which black women had completed was ten or eleven; the white women, on the average, were high school graduates who had also completed some college training.

Five of the white women, but none of the black women, were dialyzing in their own homes rather than in a dialysis facility. Data from a recent national survey of dialysis patients indicate that nonwhites are significantly less likely than whites to dialyze at home (Evans, 1979a). Home patients tend to be married (and hence to have a partner available to help with dialysis) and to be more highly educated than are facility dialysis patients, both of which help to explain the lower incidence of home dialysis among black patients.

For purposes of comparison, we will also present selected data obtained in the same study from 46 white men and 40 black men who were on maintenance dialysis therapy. Median age of white men was 43, with a range of 19 to 79; median age of black men was 47, with a range of 21 to 63. White men had been dialyzing for an average of 36.5 months; black men had been dialyzing for an average of 38.0 months. Black men (55\%) were almost as likely as white men (61\%) to be currently married. As was true for women patients, the average years of schooling completed by black men was ten or eleven; white men, on the average, were high school graduates who had also completed some college training. 


\section{Measures}

Data reported in this paper were gathered from a semi-structured interview with the patient which lasted thirty to ninety minutes, from a self-rated satisfaction scale completed by the patient, and from responses to the Zung self-rated depression scale (Zung, 1965) and the Zung anxiety scale (Zung, 1971).

In addition to demographic information, patients were asked during the interview to indicate the usual number of hours spent in homemaking activities and to rate how they felt upon arising, at mid-day, and upon retiring (a measure of fatigue level).

A self-rating scale was used to assess patients' satisfaction with their current working or homemaking situation, their feelings about themselves, and their current sexual life as compared to their satisfaction with these areas when they were well. Patients were asked to mark a point on a 100-millimeter line to describe their feelings, with 100 indicating "the same or more satisfying" and 0 indicating "not at all satisfying."

Both the self-rated depression scale and the self-rated anxiety scale developed by Zung consist of twenty Likert-type items. According to Zung (1965), an index score below 50 on the self-rated depression scale is within the normal range; from 50 to 56 indicates borderline depression, and a score greater than 56 indicates significant clinical depression. For the self-rated anxiety scale, an Index below 44 is within the normal range; from 45 to 55 indicates significant anxiety symptoms, and a score greater than 56 indicates severe anxiety symptomatology (Zung, 1971).

\section{RESULTS}

\section{Patients' Fmployment/Homemaking Status, Satisfaction, and Depression}

After beginning maintenance dialysis, the modal pattern among black women in our sample was to give up employment outside the home and devote their energy to homemaking. White women were more likely than black women to continue their pre-dialysis job or student status (Table 1). This finding seems to be a function of socioeconomic differences between the two groups of women. The greater frequency of white women maintaining a job outside the home was linked to their ability to continue clerical or teaching positions, while black women found it difficult to continue maid work and other jobs which required them to be on their feet for long periods of time. Employers of white-collar workers 
may also be more understanding about dialysis patients' need for flexible scheduling of work hours or occasional absenteeism due to health problems.

Table 1. Women Patients' Activity Status After Beginning Maintenance Dialysis

\begin{tabular}{lrrrr}
\hline & \multicolumn{2}{c}{ Black Women } & \multicolumn{2}{c}{ White Women } \\
& $\mathrm{N}$ & $\%$ & $\mathrm{~N}$ & $\%$ \\
\hline No significant level of activity & 3 & $(11)$ & 3 & $(13)$ \\
Decreased level of homemaking & 4 & $(15)$ & 4 & $(17)$ \\
Shift from employment to homemaking & 10 & $(37)$ & 4 & $(17)$ \\
$\begin{array}{l}\text { Pre-dialysis level of homemaking } \\
\text { Pre-dialysis (or better) job or } \\
\text { student status }\end{array}$ & 7 & $(26)$ & 6 & $(26)$ \\
Totals & -3 & $\underline{(11)}$ & $\underline{6}$ & $\underline{(26)}$ \\
& 27 & $(100)$ & 23 & $(99)$ \\
\hline
\end{tabular}

Black women and white women also differed in their satisfaction wth their current job or homemaking situation relative to when they were well. Among women who had given up outside employment and turned to homemaking, the average satisfaction rating was 83.4 for black women, while the average satisfaction rating for white women was 31.8 . Thus, women's reaction to a shift from employment to homemaking seems related to the nature of the job held when they were employed. Black women, who had primarily held unskilled jobs, found homemaking a more satisfying alternative than did the white women in our sample.

Women who had been able to maintain or improve their pre-dialysis job or student status were highly satisfied with their current situation. The average satisfaction rating for white women in this category was 69.3; for black women, the average satisfaction rating was 78.0 . It is interesting to note the job status of the black women In this category. One had moved from a CETA position to being a full-time college student, one continued her ten-year job at the hospital where she dialyzed, and one obtained a clerical position after a vocational rehabilitation referral steming from her participation in the research project.

Average depression scores, as measured by the Zung scale, give another perspective on patients' adjustment following initiation of dialysis therapy (Table 2). Among both women and men, depression scores were lower for employed persons than for individuals whose main activity 
was homemaking. For white women and white men, depression scores for the employed group were significantly lower than those of the homemaking group $(p<.01)$. However, the only category for whom significant clinical depression was evident was white men whose main activity was homemaking.

Table 2. Mean Depression Scores of Renal Patients, by Race, Sex, and Activity Status*

\begin{tabular}{|c|c|c|c|c|}
\hline & \multicolumn{2}{|c|}{$\begin{array}{r}\text { Black Patients } \\
(\mathrm{N})\end{array}$} & \multicolumn{2}{|c|}{$\begin{array}{r}\text { White Patients } \\
(\mathrm{N})\end{array}$} \\
\hline $\begin{array}{l}\text { Women Whose Main Activity } \\
\text { was Homemaking } \\
\text { Employed Women }\end{array}$ & $\begin{array}{l}51.26 \\
50.33\end{array}$ & $\begin{array}{r}(19) \\
(3)\end{array}$ & $\begin{array}{l}49.36 \\
39.17\end{array}$ & $\begin{array}{r}(11) \\
(6)\end{array}$ \\
\hline $\begin{array}{l}\text { Men Whose Main Activity } \\
\text { was Homemaking } \\
\text { Employed Men }\end{array}$ & $\begin{array}{l}48.40 \\
45.57\end{array}$ & $\begin{array}{r}(9) \\
(14)\end{array}$ & $\begin{array}{r}59.38 \\
.45 .48\end{array}$ & $\begin{array}{r}(8) \\
(21)\end{array}$ \\
\hline
\end{tabular}

*This table does not include patients who had no significant level of activity.

Women who said they tired easily during an average day tended to report fewer hours per week of homemaking activity; this was not a significant correlation, however.

\section{Patients' Satisfaction with Their Sexual Life}

Patients were asked to rate their satisfaction with their current sexual life compared to their satisfaction when they were well. Although decreased interest in sex and decreased ability to perform sexwally are not the only factors likely to affect satisfaction with sexual life, patients indicated during their interviews that these factors did strongly affect their satisfaction in this area.

Average sexual satisfaction ratings of black women and white women are compared with the average ratings given by men of similar race and marital status in Table 3 . In two comparisons, women's average satisfaction was higher than the average satisfaction reported by men. In one of the two remaining comparisons, however, men reported higher satisfaction with their current sexual iffe than did women, and average satisfaction ratings for men and women were quite similar in the remaining case. No statistically significant differences were found between the means shown in Table 3. 
Thus, our data do not indicate that men patients are less satisfied than women patients with their sexual life. The large majority of patients reported decreased satisfaction with their sexual life compared to their satisfaction when they were vell, and two of the mean ratings reported in Table 3 indicated that patients viewed their sexual life as "much less satisfying."

Table 3. Mean Sexual Life Satisfaction Ratings of Renal Patients, by Race, Marital Status, and Sex

\begin{tabular}{|c|c|c|c|c|c|c|c|c|}
\hline & \multirow[t]{2}{*}{$\begin{array}{r}\text { B1 } \\
\text { Married }\end{array}$} & \multicolumn{3}{|c|}{$\begin{array}{l}\text { ack Patients } \\
\text { Non-married }\end{array}$} & \multirow[t]{2}{*}{$\begin{array}{r}\text { Wh } \\
\text { Married }\end{array}$} & \multicolumn{3}{|c|}{$\begin{array}{l}\text { te Patients } \\
\text { Non-married }\end{array}$} \\
\hline & & (N) & & $(\mathrm{N})$ & & (N) & & (N) \\
\hline Women & 39.00 & (4) & 61.20 & (15) & 69.85 & (13) & 53.40 & (5) \\
\hline Men & 53.67 & (21) & 48.60 & (15) & 25.44 & (27) & 57.60 & (15) \\
\hline
\end{tabular}

Patients' Anxiety

Reichsman and Levy (1972) reported that women's concern over the fate of their children if they should die created anxiety for women dialysis patients. However, responsibility for dependent children did not appear to be related to anxiety scores among women in our sample. As measured by the Zung (1971) scale, women with the highest anxiety in our study were black women with children in the home. The average anxiety score for that group, 45.50, Indicates the presence of anxiety symptoms. However, this score was not significantly greater than the average score for black women who did not have dependent children at home (43.93). The latter score falls within the normal range specified by Zung (1971).

Regardless of whether or not they had dependent children, white women's anxiety scores were well within the normal range (39.41 for those without dependent children and 32.67 for those who did have dependent children). Thus, black women generally appeared to be more anxious, as well as more depressed, than white women in our sample. Although black men did not appear to be more depressed than white men, the average anxiety score for black men (46.57) indicated the presence of anxiety symptoms and was higher than the average anxiety score for white men (43.84). 


\section{DISCUSSION AND CONCLUSION}

In an earlier study of disabled individuals (Kutner and Kutner, 1979), we reported that the inability to perform a job was the most salient loss for all subjects. Regardless of race and sex, inability to work was regarded as the worst thing about being sick. In addition to the financial and self-esteem rewards which individuals gain from a job, renal patients in this study noted that a job has the additional benefits of giving you something to think about other than your own problems and of making you tired so that you can sleep better at night despite your physical discomforts.

In 1iterature dealing specifically with renal patients, there is often the suggestion that women fare better than men after developing ESRD because they can carry on with their housework and still feel that they are fulfilling a significant societal role as homemakers. The data reported here raise questions about the validity of this suggestion. Women dialysis patients who held rewarding jobs outside the home prior to the onset of their disability indicated a low level of satisfaction with their current homemaking role. As Nathanson (1980) notes, employment can be an important source of self-esteem for women, buffering the individual against stresses in her environment. Although black women who had formerly worked outside the home were satisfied with the homemaking role as compared to their previous job status, these women had relatively high depression scores. For white women, continuation of job or student activities after beginning dialysis was related both to high satisfaction with current status and low depression scores. Final$1 y$, homemaking chores may be difficult for women whose illness causes them to tire easily during the day. Fatigue is a frequent complaint of renal patients.

Comments offered by subjects during the semi-structured interview indicate additional difficulties associated with the homemaker role. One women stressed the need to have something to think about besides your own problems; she was especially grateful for her job because it kept her mind off herself during the day. Two women observed that it is difficult for a wife/mother/homemaker who has renal disease when so many people depend on her and continue to expect her to fulfill their needs. Her disability is not a visible one, and therefore she may not be viewed as really sick, especially by her children. As Zahn (1973) noted, there is a tendency for interpersonal relations to be impaired when the disabled role is not clearly legitimized. 
Our data suggest that women renal patients are not more satisfied with their sexual life than are men renal patients. Women patients, despite decreased sexual response, can still function as sexual partners, whereas male patients' sexual disability (impotence) is clearly defined. Research on sexual problems of renal patients has been concerned only with males (Levy, 1978b). Again, women's impairment is invisible and hence not a legitimized source of concern.

Safilios-Rothschild (1977:4) points out that "adding to the problems of being female and disabled is of ten a third factor, such as age or poverty or illiteracy." The third factor which stands out in this study is minority status (1.e. being black), which, for women in our sample, in turn implies a disadvantaged socioeconomic position and a decreased probability of being currently married. These two characteristics decrease the likelihood of dialyzing at home, which is the treatment setting associated with the best patient outcomes (Evans, 1979a). We suspect also that black women are less likely to be candidates for a kidney transplant; transplant recipients in our study to date include elght white men, seven white women, four black men, and three black women.

It appears that women have only had equal access to dialysis therapy since the ESRD program was assumed by Medicare in 1972. They now have a chance to survive which they apparently did not have before 1970 . However, inequities persist in addition to the homemaker and sexual adjustment stereotypes about female renal failure patients which have been questioned in this paper. Structural characteristics in the provision of dialysis therapy--especially home dialysis incentives, typical sex of dialysis staff and nephrologists, and Social Security benefits--seem to benefit men more than women patients.

There 1s growing interest in the use of dialysis within the home as a replacement for dialysis within hospital or clinic facilities (Atcherson and Roy, 1980: Roberts et al., 1980; Evans, 1979b). The anuual cost of home dialysis is significantly less than that of in-center dialysis, and increased use of home dialysis would therefore save the federal government a great deal of money. Home dialysis requires a willing partner/helper, however, who can take the time to participate in home training with the patient and will be available four to six hours three times a week to assist with the procedure. It is not surprising, then, that home patients tend to be men whose wives (or mothers) can serve as the partner. And if the home patient is a woman, the expectation that the patient on home dialysis should be the one primarily responsible for directing his/her dialysis may create an uncomfort- 
able reversal in the traditional dominant/subordinate husband-wife roles within the family. Perhaps barriers to use of home dialysis by women patients, as well as men patients, would be significantly decreased by Medicare coverage for a trained helper or technician to go into the home; this alternative is only avallable on a limited, experimental basis at the present time.

Dialysis staff (nurses, social workers, dieticians) are primarily female. Male patients in our sample referred to female staff as "the girls," and it was clear that men enjoyed the attention they received from these female care-givers, who checked their blood pressure during dialysis, chatted with them, and generally administered to their needs. Nephrologists, on the other hand, are primarily male, and some women patients commented on their nephrologists' failure to be sympathetic to menstrual cycle problems brought on, or increased, by dialysis therapy (Levy, 1978b).

Finally, women dialysis patients may be denled acçess to Social Security income. Women who discontinue jobs in order to raise a family are ineligible for Social Security if they have not worked for five of the last ten years. This problem is not specific to ESRD patients, but is one frequently noted by dialysis social workers.

The literature dealing with renal patients conveys the impression that ESRD is largely a male disease. If at least half of the patients who are currently on maintenance dialysis in the U.S. are women, further research on the issues raised in this paper is clearly needed.

Abram, H. S.

\section{REFERENCES}

1974 "Psychiatric reflections on adaptation to repetitive dialysis." Kidney International 6:67-72.

Anger, $D$.

1975 "The psychologic stress of chronic renal fallure and long-term hemodialysis." Nursing Clinics of North America 10:449-460.

Atcherson, E., and C. Roy

1980 "From center to home dialysis." Dialysis and Transplantation 9: 489-490.

Burns, S., and H. K. Johnson

1976 "Rehabilitation potential of a dialysis vs. a transplant population." Dialysis and Transplantation 5:54-56.

Czaczkes, J. W., and A. K. De-Nour

1968 Chronic Hemodialysis as a Way of Life. New York: Brunner/ Mazel, Inc. 
Evans, R. W.

1979a The Treatment of Ridney Disease: An Analysis of Medical Care Process, Medical Care Structure and Patient Outcomes. Unpublished Ph.D. Dissertation, Duke Untversity, Durham.

1979b"Center or home dialysis?" New England Journal of Medicine 301: 1186.

Evans, R. W., C. R. Blagg, and F. A. Bryan, Jr.

1981 "Implications for health care policy: a soctal and demographic profile of hemodialysis patients in the United States." Journal of the American Medical Association 245:486-491.

Goldberg, R. T., A. W. Bigwood, and W. Donaldson

1972 "Vocational adjustment, Interests, work values, and career plans of patients awafting renal transplantation." Scandinavian Journal of Rehabilitation Medicine 4:170-174.

Gutman, R. A., W. W. Stead, and R. R. Robinson

1981 "Physical activity and employment status of patients on maintenance dialysis." New England Journal of Medicine 304:309-313.

Kutner, N. G., H. Baker, P. Bretches, H. Chyatte, P. Fair, H. Gray, and C. Wortham

1980 "Programs and treatments: views of dialysis and transplant patients." Dialysis and Transplantation 9:1138, 1140-1142.

Kutner, N. G., and M. H. Kutner

1979 "Race and sex as variables affecting reactions to disability." Archives of Physical Medicine and Rehabilitation 60:62-66.

Levy, N. B.

1973 "Sexual adjustment to maintenance hemodialysis and renal transplantation: national survey by questionnaire." Transactions of the American Soclety for Artificial Internal Organs 19:138-143.

1978a"Psychological sequelae to hemodialysis." Psychosomatics 19:329331.

1978b"Sexual function in hemodialysis patients." In A. Comfort (ed.), Sexual Consequences of Disability. Philadelphia: George F. Stickley Company.

Nathanson, C. A.

1980 "Social roles and health status among women: the significance of employment." Social Science and Medicine 14:463-471.

Reichsman, F., and N. B. Levy

1972 "Problems in adaptation to maintenance hemodialysis: a four-year study of 25 patients." Archives of Internal Medicine 130:859865.

Roberts, S. D., D. R. Maxwell and T. L. Gross

1980 "Cost-effective care of end-stage renal disease: a billion do1lar question." Annals of Internal Medicine 92:243-248. 
Rosenfield, S.

1980 "Sex differences in depression: do women always have higher rates?" Journal of Health and Social Behavior 21:33-42.

Safilios-Rothschild, C.

1977 "Discrimination against disabled women." International Rehabilitation Review: 4.

Zahn, M. A.

1973 "Incapacity, impotence and vistble impairment: their effects upon interpersonal relations." Journal of Health and Soctal Behavior 14:115-123.

Zung, W. W. K.

1965 "A self-rating depression scale." Archives of General Psychiatry $12: 63-70$.

1971 "A rating instrument for anxiety disorders." Psychosomatics 12: 371-379. 